\title{
Positional and Cooccurrence Restrictions on Ejectives
}

\author{
Carmen Jany \\ California State University, San Bernardino
}

Different studies have looked at phonotactic restrictions on ejectives from a variety of perspectives focusing on syllable structure or on general patterns of laryngeal features, such as cooccurrence limitations or positionally motivated neutralization of contrast (Blevins 2004, Coulston 2001, MacEachern 1997, Maddieson 2004, Rimrott 2003, Steriade 1999). This paper brings together these diverse approaches suggesting that all phonotactic restrictions are based on articulatory and auditory features often working together. Given that languages vary with respect to articulatory features of their phonemes and with regard to perceptual similarity, different restriction patterns are found cross-linguistically.

Ejectives are found in about 18\% of the world's languages (Ladefoged and Maddieson 1996) with a strongly regional geographical distribution (Maddieson 2004). They occur in many languages of the Americas (especially in north-western parts of North America, in Mesoamerica, and along the Andean cordillera in South America), in southern regions of Africa, and in the Caucasus. They are completely absent from western Eurasia and Australia. In this survey, 27 languages from all three major geographical regions: the Americas, Africa, and the Caucasus, are included. Nevertheless, the majority of languages discussed (19) are from the Americas. Although the languages are found in three major areas, there is great genetic diversity, in particular among the languages of the Americas.

The materials used for this survey include grammars and secondary sources that consist of articles examining phonotactic restrictions of laryngeal features in different languages (MacEachern 1997; Rimrott 2002, 2003; Steriade, 1999). While the grammars often lack a detailed description of the phonotactic restrictions - this concerns especially the cooccurrence limitations - the secondary sources often lack distributional information which is not subject to any restriction.

Reported phonotactic restrictions for ejectives can be divided into two main types: a) ejectives do only or do not occur in certain positions (e.g. not coda position, always leftmost stop in a morpheme) and b) ejectives can only or cannot cooccur with certain segments (e.g. not with other ejectives, only with identical ejectives). Hence, the main phonotactic restrictions concern position within a syllable or word and cooccurrence with other segments within a syllable or word. Both restriction categories depend on the phonetic and phonological context, such as the types of segments that precede and follow, and can be attributed to articulatory and auditory features.

\section{Phonotactic Restrictions Based on Syllable Structure}

In a first step the phonotactic restrictions of ejectives are examined based on syllable structure. This analysis includes both: positional and cooccurrence restrictions. Positional restrictions describe the limitations of ejectives to onset or coda position and/or to word edges. The cooccurrence restrictions are based on the possible segments in tautosyllabic consonant-clusters if one of the consonants is an ejective. However, complex onsets and codas do not occur in all languages and are sometimes vaguely described in grammars. Therefore, the survey is limited in this regard.

Some restrictions are expected to occur for phonetic reasons. Given that stops are not always released in coda position (Blevins 2004), it is likely to find languages where ejectives are limited to onset position. The absence of a release eliminates all phonetic cues for ejectives contrasting with other stops. Hence, a distinction is not audible and a contrast is neutralized. In general, there are far fewer contrasts available in coda position than in onsets (Blevins 2004). Complex onsets and codas 
may also show restrictions based on articulatory and auditory features.

Information on positional restrictions is only available for 21 of the 27 languages included in this survey. Of these 21 languages, 8 do not allow ejectives in coda position. No differences between syllables at word-edges and word-internal syllables are reported for either onsets or codas. It can be assumed that languages with no positional restriction always release their stops, such as has been confirmed for Bella Coola (Blevins 2004). It can further be assumed that languages which limit ejectives to onsets do not release their stops in coda position and therefore neutralize a contrast between plain or other and ejective stops in that position.

Consonant clusters show similar restrictions in onset and coda position. One language in the survey, Dakota, does not allow ejectives in onset clusters and two languages, Dakota and Chimariko, lack ejectives in coda clusters. In Klamath, coda clusters containing an ejective cannot occur word-finally. Several languages limit the types of segments that can cooccur with ejectives in clusters. In some languages, ejectives can only precede glides or voiced sonorants in clusters regardless of position (onset or coda) and they can only follow a plain stop or a sonorant. Blevins (2004) asserts that ejectives commonly contrast with other stops before sonorants, but that they tend to neutralize before obstruents and word-finally. Steriade (1999) affirms that ejectives depend for optimal identification of its laryngeal category on the right-hand context because they are postglottalized. This explains the restrictions to the segments following an ejective in clusters, but it does not offer an explanation for the limitations to the segments preceding an ejective in clusters. A possible reason for the limitations to the left-hand context in some languages is articulatory complexity. In Bella Coola two ejectives cannot cooccur in a cluster. This restriction bans adjacent laryngeally-marked consonants. A possible explanation lies in the articulatory difficulty and the perceptual complexity.

Several studies (MacEachern 1997; Rimrott 2003; Steriade, 1999) have demonstrated that phonotactic restrictions of ejectives cannot be explained in terms of syllable structure alone, but that they are based primarily on articulatory and auditory features. These studies often discuss additional restrictions not mentioned in grammars, such as the limitations to the cooccurrence of certain segments.

\section{Phonotactic Restrictions Based on Position and Cooccurrence}

Many of restrictions on ejectives are positional and cooccurrence restrictions independent of the syllable, confined to the domain of the word or morpheme. This shows that phonotactic restrictions cannot always be explained in terms of syllable structure. Other factors, such as phonetic cues and articulatory features, offer more general explanations for the reported restrictions.

There are no restrictions reported for 6 of the 27 languages in this survey. For 5 of the languages, the restrictions are based on syllable structure. Most of the languages with no or only syllable-based restrictions are found in the north-western United States and the information stems mainly from grammars. The remaining 16 languages have restrictions based on position within a domain (usually the morpheme or the word) and cooccurrence of segments within a domain (usually the morpheme or the word).

The positional restrictions place ejectives to the left edge of a domain, hence to a perceptually more salient position. Slave allows only stem-initial ejectives and in Cuzco Quechua, Peruvian Aymara, and Bolivian Aymara ejectives are always the leftmost stop in a morpheme. This coincides in part with having ejectives only in onsets where stops are always released. Apart from articulatory reasons, onset position is also perceptually more salient than coda position.

The cooccurrence restrictions are based on similarity issues. While some languages allow only similar segments, e.g. homorganic segments or segments with the same laryngeal specification, others allow only dissimilar segments. Again others allow only identical segments to cooccur. For 
example, Dakota, Cuzco Quechua, and Peruvian Aymara do not have ejectives and aspirated stops cooccurring within a domain, while Bolivian Aymara, Hausa, and Old Georgian, do not have ejectives and homorganic aspirated stops occurring together. The latter ones ban the cooccurrence of very similar segments within a domain. Some languages, such as Hausa and Tzutujil, do not allow homorganic plain and ejective stops within a domain. Ejectives can only cooccur with other ejectives in a few languages and with certain restrictions. Many languages ban the cooccurrence of ejectives within a morpheme or root, such as Shuswap, Cuzco Quechua, Peruvian Aymara, Bolivian Aymara, and Tzutujil. In the latter three languages two cooccurring ejectives are allowed if they are identical.

MacEachern (1997) states that the cooccurrence restrictions are based on auditory similarity and identity. She describes four patterns. Each pattern represents a subset of restrictions of the next identified pattern forming an implicational hierarchy. MacEachern (1997) places Tzutijil and Shuswap in pattern 4, the pattern with the most restrictions, where only extremely similar elements are prohibited from cooccurring, but identical segments can cooccur. Bolivian Aymara, Old Georgian, and Hausa show restrictions based on pattern 3, Peruvian Aymara belongs to pattern 2, and Cuzco Quechua behaves like pattern 1 allowing only very dissimilar elements within a domain. Cooccurring elements can be placed on a scale of similarity from identical to completely dissimilar. The patterns described by MacEachern (1997), however, do not show that elements on only one side of the scale are favored, but rather that elements from both sides can cooccur banning segments from the middle of the scale, given that identical and very dissimilar elements are found together in certain languages (e.g. pattern 4).

The cooccurrence limitations also include restrictions based on syllable structure, in cases where certain segments cannot cooccur next to each other, e.g. in clusters. In Bella Coola, no consonant cluster can contain two ejectives. Chaha, Georgian, and Mingrelian allow only adjacent stops with the same laryngeal specification. In many languages, ejectives are not found next to a glottal stop, as in Cuzco Quechua and Hausa. Again, these restrictions are based on similarity. While some languages allow similar segments next to each other, others ban them.

\section{Summary and Conclusions}

All phonotactic restrictions described for the languages in this survey can be categorized as positional or cooccurrence restrictions. Positional limitations place ejectives either in onset position, such as in a syllable-based approach, or at or close to the left edge of a domain. The motivations for these restrictions either have an articulatory basis, such as the lack of a stop release in coda position, or an auditory basis, such as having marked segments in a perceptually more salient position. Articulatory and auditory reasons often work together. The lack of an audible release in coda position eliminates the primary phonetic cues for the perception of a contrast resulting in laryngeal neutralization.

Cooccurrence limitations show similar tendencies. All cooccurrence restrictions are based on auditory similarity. However, languages differ in where they set the point at which similarity becomes unacceptable. Hence, similarity is gradient across languages. In some languages, identical elements may cooccur, but very similar ones do not. In others, similar elements may be found together, but dissimilar ones are not. Languages also vary with respect to the domain of the restriction. While some phonotactic cooccurrence restrictions are based on roots or morphemes, others depend on syllables or words.

It seems then that all phonotactic restrictions of ejectives can be explained in terms of articulatory variation and ease and on perceptual complexity and similarity. Nevertheless, more cross-linguistic phonetic analysis is needed to have experimental confirmation of these tendencies. 


\section{References}

Asher Dunn, John. 1995. Sm'algyax: A Reference Dictionary and Grammar for the Coast Tsimshian Language. Seattle: University of Washington Press.

Blevins, Juliette. 2004. Evolutionary Phonology: The Emergence of Sound Patterns. Cambridge University Press: Cambridge.

Coulston, Rachel. Ejective reduction in Chaha is conditioned by more than prosodic position. www.cse.ogi.edu/CHCC/Publications/ejective_reduction_in_chaha_coulston.pdf

Golla, Victor. 1960. Hupa Grammar. Dissertation, University of California, Berkeley.

Good, Jeff. 2004. A sketch of Atsugewi phonology. Presented at the annual winter meeting of SSILA. Boston, January 8-11, 2004.

Haspelmath, Martin. 1993. A Grammar of Lezgian. Berlin: Mouton.

Hewitt, B. G. 1995. Georgian: A Structural Reference Grammar. Amsterdam: John Benjamins.

Jany, Carmen. 2009. Chimariko Grammar: Areal and Typological Perspective. University of California Publications in Linguistics Vol. 142. Berkeley: University of California Press.

Ladefoged, Peter \& Ian Maddieson. 1996. The Sounds of the World's Languages. Oxford: Blackwell. Leslau, Wolf. 1995. Reference Grammar of Ambaric. Wiesbaden: Harrassowitz.

Maceachern, Margaret. 1997. Laryngeal Cooccurrence Restriction. Dissertation. University of California, Los Angeles.

Maddieson, Ian.

1984. Patterns of Sounds. Cambridge: Cambridge University Press.

2004. Glottalized consonants. WALS (unpublished)

Nater, H. F. 1984. The Bella Coola Language. Ottawa: National Museum of Canada.

Newman, Paul. 2000. The Hausa Language: An Encyclopedic Reference Grammar. London: Yale University Press.

Pitkin, Harvey. 1984. Wintu Grammar. University of California Publications in Linguistics Vol. 94. University of California Press: Berkeley.

Raz, Shlomo. 1983. Tigre Grammar and Texts. Malibu: Undena Publications.

Rice, Keren. 1989. A Grammar of Slave. Mouton Grammar Library 5. Mouton de Gruyter, New York.

Rimrott, Anne. 2003. An Optimality Theoretic Analysis of Ejective Stops in Klamath, Dakota, Quechua, Chaha, and Mingrelian. www.sfu.ca/ arimrott/

Robins. R.H. 1958. The Yurok Language: Grammar, Texts, Lexicon. University of California Publications in Linguistics Vol. 15. University of California Press: Berkeley.

Sapir, Edward and Morris Swadesh. 1960. Yana Dictionary. University of California Publications in Linguistics Vol. 22. University of California Press: Berkeley.

Shipley, William F. 1964. Maidu Grammar. University of California Publications in Linguistics Vol. 41. University of California Press: Berkeley.

Silver, Shirley. 1949. The Shasta Language. Dissertation, University of California, Berkeley.

Steriade, Donca. 1999. 'Phonetics in Phonology: The Case of Laryngeal Neutralizaton'. Matthew Gordong ed., UCLA Working Papers in Linguistics, Vol. 2, Papers in Phonology.

Watkins, Laurel J. 1984. A Grammar of Kiowa. University of Nebraska Press. 